\title{
Adoption of technological innovations in the m-commerce industry
}

\author{
Vanessa Ratten \\ Management Division, \\ Palumbo Donahue School of Business Administration, \\ Duquesne University, \\ 464 Rockwell Hall, 600 Forbes Avenue, \\ Pittsburgh 15282, Pennsylvania, USA \\ E-mail: vanessaratten@gmail.com
}

\begin{abstract}
The banking industry has globalised as a result of the many technology innovations created by the internet. The electronic commerce (e-commerce) industry is a result of these technological innovations that have revolutionised the way both consumers and businesses conduct business. In the past decade, banks have encouraged the use of e-commerce and most people are now comfortable conducting their banking online. More recently, mobile commerce (m-commerce) has started to gain momentum and an increasing amount of people are conducting their banking on mobile phone devices instead of through the internet. Mobile banking is a technological innovation that people adopt in different ways depending on internal and external environmental influences. In this paper, a social cognitive theoretical framework is adopted to understand an individual's intention to adopt mobile banking. A conceptual model is proposed, which helps to explain how environmental influences affect an individual's intention to adopt mobile banking. Implications for mobile banking and $\mathrm{m}$-commerce industry are stated along with suggestions for future research on technological innovations.
\end{abstract}

Keywords: mobile banking; banks; mobile marketing; technological innovations; behavioural intentions; social cognitive theory.

Reference to this paper should be made as follows: Ratten, V. (2009) 'Adoption of technological innovations in the m-commerce industry', Int. J. Technology Marketing, Vol. 4, No. 4, pp.355-367.

Biographical notes: Vanessa Ratten is an Assistant Professor at Duquesne University, Pittsburgh. She has published in numerous journals including the Asia Pacific Journal of Marketing and Logistics, International Journal of Entrepreneurship and Small Business, Journal of High Technology Management, European Journal of Innovation Management, Journal of Management and Organization, International Journal of Educational Management, Thunderbird International Business Review and the International Journal of Innovation and Technology Management. She has co-edited a book entitled Handbook of Research on European Entrepreneurship (Edward Elgar, 2008) and Handbook of Research on Asian Business and Entrepreneurship (Edward Elgar, 2009). Her research interests include entrepreneurship, sports and technology.

Copyright (C) 2009 Inderscience Enterprises Ltd. 


\section{Introduction and background}

The technological innovations created by the internet have meant that most banking products and services are now available online via a banks' website (Ratten, 2008). Electronic commerce (e-commerce) has enabled banks to communicate and conduct business via a technological device rather than via a face-to-face transaction (Wymbs, 2000). The most common way e-commerce has enabled banks to communicate about their products and services is through electronic payment systems. As most people now have mobile phones this has created another way for banks to communicate information about their services (Holland, 2008). Mobile commerce (m-commerce) has been defined by Snowden et al. (2006, p.525) as "the integration of mobile computing devices into business processes". Harris et al. (2005, p.210) further explain m-commerce as "the use of mobile wireless (handheld) devices to communicate and conduct transactions through public and private networks" and this definition is adopted in this paper.

$\mathrm{M}$-commerce is important for the banking industry as it allows time and space advantages (Barnett et al., 2000). There are time advantages in the way banks market their products and services as real time mobile phone messages can be sent directly to customers (Seitz and Stickel, 1998). In the past, the only way banks could market their products and services was through mass advertising campaigns on the television or in the print media that were not personalised to individual customers. There are space advantages for banks in terms of enabling people to conduct their banking via a small technology device rather than a computer (Holland, 2008). Moreover, as internet capabilities are becoming more common on mobile phones, more people will be able to do their banking via their mobile phone. People are now trusting e-commerce to conduct their banking and the use of $\mathrm{m}$-commerce is becoming more common.

Mobile phone networks cover more than $80 \%$ of the world's population (Taylor, 2007). In addition, more than three billion people have a mobile phone so this creates an enormous opportunity for banking institutions to use mobile phone technology (Taylor, 2007). Recently, Western Union and GSM Association, which is a mobile phone operator body, signed a deal to collaborate on financial transactions conducted through mobile phones (Taylor, 2007). In this deal, more than 800 million customers in more than 100 countries can transfer money via their handsets.

Transferring money through mobile phones is particularly attractive to people who are expatriates and immigrant workers who wish to transfer money home. People who utilise mobile phones can send and receive low-denomination but high frequency money transfers. Many people do not have a bank account so transferring money via mobile phone is a potentially vast and lucrative market for banks.

In the global marketplace, mobile handsets are ubiquitous (Riivari, 2005). Riivari (2005, p.11) states "there are three times as many mobile phone users as online PCs and they are banking very sophisticated and demanding users". People have become more accustomed to using their mobile phones at anytime and anywhere. Mobile phones are preferred means of communication for most people and increasingly, they are being used more for business transactions that bring economic benefits. The usages of mobile phones are numerous and include providing real time price data and making communication easier.

Mobile banking is now faster and more affordable than it has been in the past. People are increasingly having more mobile lifestyles and are actively seeking out additional 
services for their mobile phones. Mobile banking is also as safe as online banking as mobile phone companies utilise Meridea mobile banking software (Riivari, 2005). Mobile banking enables financial institutions to attract new customers. Mobile banking also enables banks and consumers to communicate directly about other financial service products such as loans.

Mobile banking allows individuals total independence in terms of their time and place they do their banking. Wireless technology means that for business, mobility does not limit productivity (Lu et al., 2003). Aungst and Wilson (2005, p.59) define wireless communication as "the process of communicating information in electromagnetic media over a distance through the free-space environment, rather than through traditional wired or other physical conduits". Wireless communication is particularly important for the banking sector as it allows people to utilise their mobile phone to do their banking. The $\mathrm{m}$-commerce industry is expected to be the next major technological innovation in the banking industry.

There are a number of different usages of mobile banking. Individuals can deposit and withdraw money via their mobile phone operator. They can also send money to other people via text messages, which can be exchanged for money by visiting a recognised mobile phone agent. People can be pay via their mobile phone and utilise their mobile phone like an ATM card. In addition, mobile banking will enable people that have not had access to banking before because of the rigid rules required by some banks to open an account to open new accounts (Snowden et al., 2006).

This paper contributes to the gap in the technological innovation literature on new m-commerce applications that will impact the banking sector. Prior research has called for more work on mobile banking as an important technological innovation (e.g., Murmann and Frenken, 2006; Ratten, 2008; Salo and Karjaluoto, 2007). The aim of this paper is to examine the factors that help to explain and understand why people adopt mobile banking and how they can be influenced to adopt this technological innovation faster. This paper argues that both internal and external environmental factors influence an individual's willingness to adopt mobile banking. Internal environmental factors are individuals' belief system and external environmental factors are culture and marketing.

The emphasis within this paper is to understand what impacts an individual's intention to utilise mobile technology for their banking. As new technologies come into the market, it is important particularly for banks and other financial institutions to understand how they can utilise technology more efficiently. The conceptual model in this paper explains in part the adoption process of m-commerce technology. Thus, the conceptual model extends the current literature on technological innovations within the $\mathrm{m}$-commerce industry by proposing that social cognitive theory in terms of understanding behavioural intentions of individuals is helpful to practitioners wanting to know how to best market and utilise their technologies in the rapidly changing global business environment. The research question of this paper is: what influences an individual's intention to adopt mobile banking?

This paper is organised in the following way. Firstly, a literature review on technological innovations in the m-commerce industry is conducted. The theoretical framework of social cognitive theory is justified and explained in terms of why it is the most appropriate to understand behavioural intentions individuals have of adopting a new technological innovation, mobile banking. Next, the conceptual model, which includes the environmental factors of culture, marketing and belief system is explained in terms of how they affect the time it takes for an individual to adopt mobile banking. The 
propositions included within the conceptual model are stated and the implications for practitioners within the banking industry are justified. Lastly, suggestions and directions for future research are highlighted, which illustrate the importance of mobile banking as a technological innovation that will have a profound impact on the m-commerce industry.

\section{Literature review}

Technological innovations involve the creation of a new product or service through the use of an existing technology (Birkinshaw and Mol, 2006). The process of technological innovation is defined by Cantisani (2006, p.1295) as "the sequence of activities undertaken to generate new techniques with the help of the sciences and their method". Technological innovations enable new ideas, objects or procedures to take place or updated for an alternative use (Rogers, 1995). In some cases, the innovation supersedes previous technology but it can also coexist with existing technology and create additional technological innovations (Rycroft, 2006).

Technological change enables human lives to be changed by scientific knowledge (Cantisani, 2006). Knowledge in the form of technological innovation alters human behaviour (Kock, 2004). Individuals learn about new processes through the knowledge obtained about technological innovations (Chan and Lu, 2004). Often, individuals learn more through their social groups, which have the expertise that enables them to use a new technology (LaRose and Eastin, 2004). In addition, people learn by observing others in their social group about the easiest way to use a new technology ( $\mathrm{Li}$ et al., 2007). These social groups allow an individual to change their own behaviour (LaRose and Eastin, 2004).

An individual's behaviour is a result of a response to certain stimuli (Bandura, 1989). Behavioural models of learning suggest that an individual reacts through problem solving (Schiffman and Kanuk, 2000). Another model of learning is cognitive, in which individuals respond to environmental conditions instead of stimuli. In this paper, the conceptual model proposed includes different environmental conditions thereby taking a cognitive learning approach. Particularly with technological innovations like mobile banking, it is important to acknowledge a number of different environmental drivers of an individual's intention to adopt a new technology (Scholnikoff, 2001).

Whilst there are other theoretical frameworks that could be used to explain an individual's intention to adopt mobile banking such as the technology acceptance model, I utilise social cognitive theory as the theoretical framework in this paper. Social cognitive theory is a type of cognitive learning model. Unlike behavioural learning models, which suggest that behaviour takes place as a response to external stimuli, cognitive learning models stress that behaviour occurs before the response to the external stimuli has occurred (Schiffman and Kanuk, 2000). This distinction is particularly important in evaluating an individual's intention to adopt mobile banking as there are a variety of different stimuli that an individual will and will not be influenced by. Social cognitive theory is a type of social learning behaviour as it implies that an individual is influenced by both individual and group behaviour (Pincus, 2004). Individuals influence their own behaviours through a variety of actions that they can partake in (McCormick and Martinko, 2004). People learn about mobile banking through a variety of different sources that are also influenced by an individual's culture and country context. Moreover, 
social cognitive theory emphasises that an individual needs to have skills and confidence to adopt a technology (Compeau et al., 1999).

Cognitive learning theories that apply to technological innovations include the technology acceptance model, the theory of planned behaviour, the theory of reasoned action and social cognitive theory. Social cognitive theory is used as the conceptual framework for the analysis of the model presented in this paper, as it provides a stronger theoretical foundation for understanding the adoption of technological innovations in the m-commerce industry as compared to the other cognitive learning theories. The next section will compare the benefits and shortcomings of the other cognitive learning theories and why social cognitive theory best suits the research topic of this paper.

The technology acceptance model was first proposed by Davis (1989) to explain the acceptance of information systems though modelling user acceptance (Chan and $\mathrm{Lu}$, 2004). This theory was one of the first to try and understand how people accept new technologies and can help to explain if a person will accept that they can utilise mobile banking but not why or how they will begin to use mobile banking. The benefit of the technology acceptance model is that it takes into account how an individual uses a technology and how useful they find the technology (Venkatesh and Davis, 1996). However, a shortcoming of the technology acceptance model when it was first proposed was that it did not stress antecedent factors that affect an individual's intention to adopt a new technology (Chan and $\mathrm{Lu}, 2004)$. These antecedent factors affecting an individual's intention to adopt mobile banking include whether it is socially accepted in their culture to use this technology and what kind of marketing their banking institution has undertaken to encourage them to utilise mobile banking. In order to include antecedent factors, the technology acceptance model has now been extended to include perceived usage and ease of usefulness of a technology through focusing on usage intention through social influence processes and cognitive instrumental processes (Venkatesh and Davis, 1996). A further criticism of the technology acceptance model has been its simplicity as it decreases the comprehensive understanding of behaviour intention (Taylor and Todd, 1995). In contrast to the technology acceptance model, social cognitive theory acknowledges the complex nature of behaviour intention and that individuals are impacted by the beliefs they have, about the potential benefits of mobile banking, their culture and the time it takes for marketing to focus on this technological innovation. Social cognitive theory goes beyond the technology acceptance model by examining the reciprocal interaction between the environment in which an individual operates and their behaviour (Bandura, 1986). Ajzen (1985) proposed the theory of planned behaviour to include behaviour that is not under volitional control. A criticism of the theory of planned behaviour is that its predictive ability is limited as it assumes that behaviour is pre-planned and not subject to change (Mathieson, 1991). Fishbein and Ajzen (1975) first proposed the theory of reasoned action and is a widely validated intention model that explains and predicts behaviour (Chan and $\mathrm{Lu}, 2004$ ). The benefit of the theory of reasoned action is that it states that an individual will be influenced by their own attitudes and other people's attitudes of what they think they should do (Chan and $\mathrm{Lu}, 2004$ ). However, a shortcoming of the theory of reasoned action is that it does not adequately explain when behaviour is not under an individual's control (Chan and Lu, 2004). Thus, in this paper social cognitive theory is adopted as it involves an encompassing analysis of behavioural intention towards an individual's intention to use mobile banking. Social cognitive theory incorporates some of the other cognitive learning theories and is best utilised to understand how an individual will adopt mobile banking. Social cognitive 
theory focuses more on environmental influencers of human behaviour than the other cognitive learning theories.

Social cognitive theory stresses that through learning and observing others an individual can influence their own behaviour (McCormick and Martinko, 2004). The role that social learning plays in encouraging people to increase their learning rate by observing others is highlighted in social cognitive theory (Pincus, 2004). An individual's social group influences the expectation an individual has, about their own behaviour. As an individual's behaviour, is a result of a number of different environmental factors; it is also important to highlight the complexity of cognitive learning. Individuals constantly learn in different ways that are impacted by their current and future behaviour (Kock, 2004). Social cognitive theory is a useful foundation to understand human behaviour as it acknowledges that people are impacted by events and experience (Compeau et al., 1999). The conceptual model proposed in the next section is based on social cognitive theory as it allows for an understanding of how an individual will adopt mobile banking.

\section{Conceptual model}

Often, individuals engage in certain behaviour as a result from interacting with external and internal stimuli (Chan and Lu, 2004). These stimuli are influenced by an individual's social group (Ratten and Ratten, 2007). Social cognitive theory is the theoretical framework underpinning the conceptual model. In the conceptual model, the drivers of an individual's intention to adopt mobile banking are examined. The conceptual model states that the main drivers proposed by the extant literature on technological innovations are culture, marketing and belief system, which are influenced by the time taken by an individual to adopt mobile banking. The conceptual model is a dynamic and retroactive model in which culture, marketing and a person's belief system influence an individual's intention to adopt mobile banking. Marketing has an impact on cultural perceptions as well as on belief systems of consumers, which in turn affect an individual's intention to adopt mobile banking.

Individuals are influenced by their culture and the ability of them to access emerging technology. Moreover, an individual is influenced by the marketing they receive about mobile banking. There are a variety of marketing that an individual receives about technological innovations and they include print media, television and online advertisements. The belief an individual has about their ability to use mobile banking influences their adoption behaviour. The belief of a person to use and benefit mobile banking is influenced by the time taken to learn about the technology. When there is time efficiency in learning about mobile banking, the intention rate will be higher.

Technological innovations have increased in the past decade as the time needed to develop a new product or service has been reduced (Lundvall and Borras, 1999). This is due largely to the product life cycle becoming shorter, which enables the commercialisation of products to become quicker (Rycroft, 2006). As time is often used as a strategic tool by business, governments around the world are seeing technological innovations as a time saving solution that enables faster economic progress (Scholnikoff, 2001). New products and services can be developed through a time efficient process (Rycroft, 2006). In addition, the time taken to introduce technological innovations to the market has decreased (Griffin, 1997). 
Technological innovations made possible by scientific developments change existing technology, but it takes time for companies to adjust to unfamiliar technology (Rycroft, 2006). Some companies require substantial changes to existing company structures and processes before they implement technological innovations (Ehrnberg, 1995). Other companies take the approach of entering into a collaborative relationship with another company in order to lessen the time and cost of implementing a technological innovation (Ehrnberg and Jacobsson, 1996). Many companies in industries that are constantly changing place an emphasis on time in order to remain competitive in the marketplace (Brown and Eisenhardt, 1997) and for their organisational survival (Rycroft, 2006). Previous research stresses the time taken for innovations to be adopted by individuals is an important aspect of the adoption process (e.g., Roddick, 2003; Rycroft, 2006). Time has become even more important in facilitating innovation in the global business environment (Stalk and Hout, 1990). The conceptual model below proposes that culture, marketing and belief system influence an individual's intention to adopt mobile banking, which is mediated by time.

Figure 1 Conceptual model

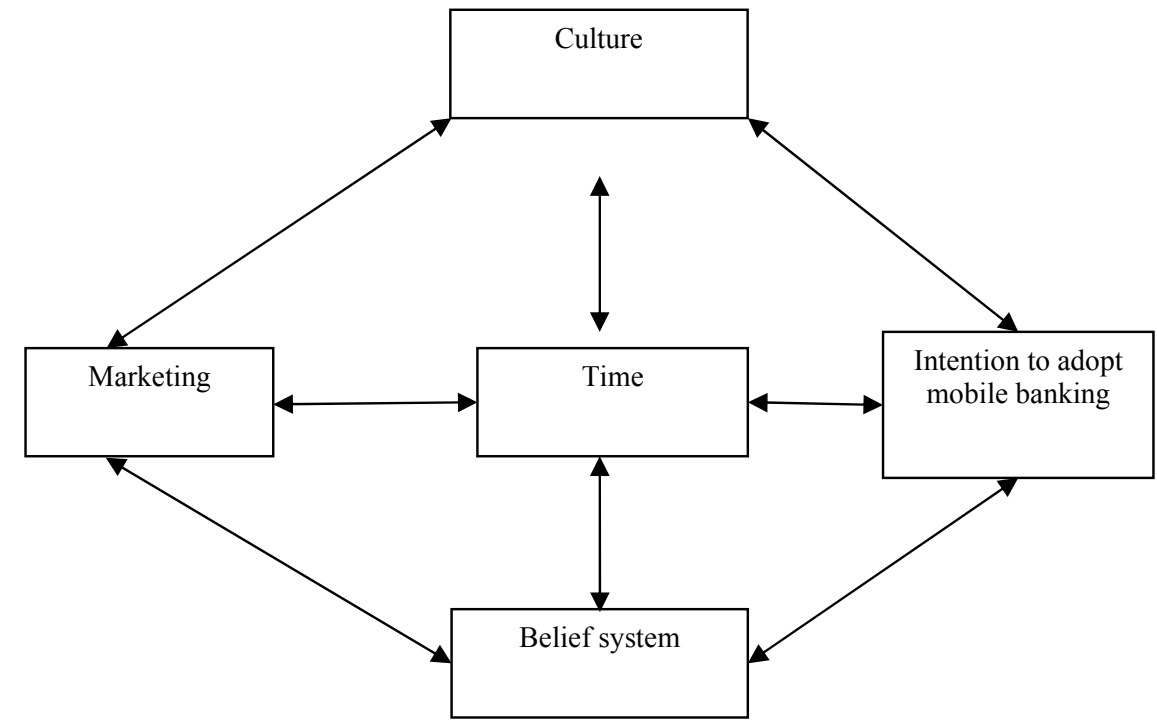

\subsection{Culture}

The adoption of m-commerce services is different amongst various countries (McCoy et al., 2007). The culture of consumers that utilise m-commerce services may influence the adoption rate of mobile banking. How culture might influence consumer behaviour is still a largely unanswered question. The usage of a mobile device depends on collective use of a mobile network (Takac, 1997). Thus, I propose that cultures that are more collectivist in nature are more likely to use mobile banking.

In Finland, people can pay for public transport via their mobile phones. In Australia, people can buy candy and ice cream from vending machines via their mobile phones. In France, mobile banking is standard at all large French banks including Societe Generale, 
Banques Populaires and Credit Mutual (Riivari, 2005). In the UK, online banks such as First Direct that do not have any branches have focused on developing mobile banking services. In Belgium, Dexia Bank has collaborated with mobile phone company Mobistar to create a mobile banking facility (Riivari, 2005). In China, the Bank of China has a wireless banking system with China Mobile.

In the Philippines, the government works closely with the banks and mobile phone operators of the countries mobile banking schemes to ensure that there is flexibility within the regulation of the mobile banking sector. In the USA, the majority of people have mobile phones with more than $80 \%$ of the population having a mobile phone. In 2007, the Bank of America had more than half a million subscribers to its mobile banking services and the update of mobile banking services in the USA is expected to be large. This leads to the first proposition:

Proposition $1 \quad$ An individual's culture, which is influenced by marketing and the belief system they have about the time taken to adopt mobile banking, has a positive impact on their intention to adopt mobile banking.

\subsection{Marketing}

The way mobile banking is marketed influences how quickly an individual will adopt new technology (The Economist, 2007). The more resources devoted to marketing technology has a social impact factor in terms of people wanting to be involved in well funded projects (Snowden et al., 2006). Mobile banking allows an individual the privacy of conducting a banking transaction (Laukkanen, 2007). In addition, mobile banking is marketed at increasing an individual's self prestige, which is influenced by lead users or early adopters of mobile banking. Often, early adopters of technology impact the effectiveness of a marketing campaign. Mobile banking as it is a technological innovation increasing in popularity is influenced by how people who are early adopters encourage or promote the usage of mobile banking.

Individuals are exposed to a variety of technologies in their everyday life (O'Bannon, 2001, Ratten, 2008). This exposure is often in the form of marketing from television or word of mouth. Marketing is an external environmental factor that influences whether an individual will try mobile banking. Banks can conduct product placements in movies and television to show how mobile banking is used. Exposure to product usage (Rogers, 1995) and the media (Sheth et al., 1999) will influence an individual's behaviour. The more exposure an individual has to advertisements about mobile banking or seeing others use mobile banking, the more likely they are to emulate this behaviour.

Prior research suggests that people often imitate the actions of others, which influences their decision to adopt new technology (Celsi et al., 1993; McCormick and Martinko, 2004). By copying the actions of others that use mobile banking, individuals share their consumption habits with their social group. An individual's social group includes friends, family and work colleagues who share consumption habits with one another (Ratten and Ratten, 2007). By sharing consumption habits indirectly, an individual's intended behaviour is likely to change (Herr et al., 1991). New behaviours then develop from the more marketing and exposure an individual has to different kinds of information (Mizerski, 1982). An individual is likely to adopt mobile banking when they have more exposure to technological innovations (Ratten, 2008). 
Marketing is an important determinant of an individual's behavioural intention (Jeffres and Atkin, 1996; Kaufman, 1991). Technological innovations constantly change the way products and services are marketed (Khan and Ghani, 2004). An individual's intention to use mobile banking will be influenced by the information they receive through different marketing mechanisms about mobile banking. This leads to the second proposition:

Proposition 2 The more marketing an individual receives about mobile banking, which is influenced by their culture and belief system, the more likely an individual is to use mobile banking.

\subsection{Belief system}

An individual's belief about the usefulness and ease of use of technology influences the implementation of technology ( $\mathrm{Lu}$ et al., 2003). The intention to adopt mobile banking is neither straightforward nor is there a set of one dimensional factors that can definitively justify and explain how an individual reacts to new technology. Individuals have different beliefs about how a technology will affect them (Rice and Bennett, 1998). Some individuals have a strong belief that they can utilise any type of technology and are more likely to try new technologies. Individuals that use technology frequently are more likely to try a new technology (Guan et al., 2006). In addition, people who have a higher usage of technology have a great belief that the technology will achieve the outcomes they desire (Henry and Stone, 1999).

An individual's self belief is also referred to in the literature as self-efficacy (Bandura, 1986). Self-efficacy often determines whether an individual will try a new product or service (Wexler, 2001). Self-efficacy is an important determinant of a person's behaviour (Fishbein and Ajzen, 1975). An individual's value system indicates the behaviour they will engage in (Bandura, 2001). When this value system includes a high self belief then the individual will conduct more complex tasks (Bolt et al., 2001). The value system an individual has will include inferences about the results of trying a new product (Folkes, 1988). New products and services are evaluated by an individual's self belief system (Bandura, 2001). An individual that believes their actions are valued will have a greater propensity to adopt new technology. This leads to the next proposition:

Proposition 3 The more an individual believes they can use mobile banking, which is influenced by the marketing and belief system they have, the greater their intention to adopt mobile banking.

\section{Implications and suggestions for future research}

This paper has examined how the technological innovation in the form of mobile banking is adopted by an individual and the reasons why an individual may be influenced to use this technology faster. The conceptual model proposed in the paper argues that the most important environmental factors influencing the time it takes an individual to use mobile banking are culture, marketing and belief system. The literature reviewed in this paper supports the propositions suggested by the conceptual model. This paper extends the 
existing literature on technological innovations by stressing the importance of both external and internal environmental factors in influencing the adoption of mobile banking.

To enable more people to utilise mobile phones governments around the world can issue new mobile phone licences and decrease taxes on mobile phones. Governments can encourage mobile banking by having the right regulations that protect users, discourage money laundering and allow new services to emerge. Many people around the world do not have access to the internet but have a mobile phone. These people who might not have entered a traditional bank in the past can utilise their mobile phone at a small fee to do their banking. Most of these people are in developing countries and the market for mobile banking in these countries is large. There may also be some significant differences in terms of culture, marketing and beliefs between developed countries and emerging ones. For example, the culture of both India and China have encouraged more male births than female and the marketing campaigns in these countries will need to focus on the gender differences and stereotypes that will affect whether a person adopts mobile banking. In addition, the social stigma associated with the caste system in India may encourage the use of mobile banking as an alternative to going to traditional shop fronted bank outlets that may be inaccessible to people from a low caste. Future research should examine these differences in culture, marketing and belief systems between developed countries and emerging ones to see if an individual's intention to adopt mobile banking is influenced by the type of country where it will take place.

More research work is required on the transition process individuals undergo when adopting mobile banking. Whilst the conceptual model in this paper proposed that the intention of an individual to use mobile banking depends on the time taken by them, their culture, the marketing that is available and their individual belief system, more research is required on the process of transitioning to mobile payments. Future research needs to examine the learning curve that exists for mobile phones that are used for mobile banking. Individuals will need to change their perception of mobile phones from something that is only used to talk on to something that can be used for commerce. In addition, for marketing managers of banks more research should be conducted on how the perception of mobile banking as a trustworthy commerce device can be increased. The way in which banks can educate individuals about the uses of mobile phones is also a fertile research area of inquiry.

The market for mobile banking is rapidly increasing and the banks that encourage individuals to utilise it, will have a first mover advantage in the marketplace. As individuals become more familiar with mobile phone technology it is important for banks to differentiate themselves in the marketplace. This paper provides a useful basis for banks that want to know how to market their mobile banking services better and how individuals will adopt mobile banking more quickly. A longitudinal study could be conducted on how people adopt mobile banking in order to see how the conceptual model proposed in this paper works in real life. This paper has focused on mobile banking but it would also be interesting for future research to examine other innovative technologies that are being adopted by the banking sector. The same conceptual model proposed in this paper could be extended to other types of technologies to examine the behavioural intentions an individual has to adopt $\mathrm{m}$-commerce applications. 
Adoption of technological innovations in the m-commerce industry

\section{References}

Ajzen, I. (1985) 'From intentions to actions: a theory of planned behavior', in Kuhl, J. and Beckman, J. (Eds.): Action-Control: From Cognition to Behavior, pp.11-39, Springer, Heidelberg.

Aungst, S.G. and Wilson, D.T. (2005) 'A primer for navigating the shoals of applying wireless technology to marketing problems', The Journal of Business and Industrial Marketing, Vol. 20, Nos. 2/3, pp.59-69.

Bandura, A. (1986). Social Foundations of Thought and Action: A Social Cognitive Theory, Prentice-Hall, New Jersey.

Bandura, A. (1989) 'Human agency in social cognitive theory', The American Psychologist, Vol. 44, No. 9, pp.1175-1184.

Bandura, A. (2001) 'Social cognitive theory: an agentic perspective', Annual Review of Psychology, pp.1-26.

Barnett, N., Hodges, S. and Wiltshire, M. (2000) 'M-commerce: an operators manual', McKinsey Quarterly, Vol. 3, pp.163-173.

Birkinshaw, J. and Mol, M. (2006) 'How management innovation happens', MIT Sloan Management Review, Vol. 47, No. 4, pp.81-89.

Bolt, M., Killough, L. and Koh, H. (2001) 'Testing the interaction effects of task complexity in computer training using the social cognitive model', Decision Sciences, Vol. 32, No. 1, pp.1-19.

Brown, S.L. and Eisenhardt, K.M. (1997) 'The art of continuous change: linking complexity theory and time-paced evolution in relentlessly shifting organizations', Administrative Science Quarterly, Vol. 42, No. 1, pp.1-34.

Cantisani, A. (2006) 'Technological innovation processes revisited', Technovation, Vol. 26, pp.1294-1301.

Celsi, R., Rose, R. and Leigh, T. (1993) 'An exploration of high-risk leisure consumption through skydiving', Journal of Consumer Research, Vol. 20, No. 6, pp.1-23.

Chan, S. and Lu, M. (2004) 'Understanding internet banking adoption and use behavior: a Hong Kong perspective', Journal of Global Information Management, Vol. 12, No. 3, pp.21-43.

Compeau, D., Higgins, C. and Huff, S. (1999) 'Social cognitive theory and individual reactions to computing technology: a longitudinal study’, MIS Quarterly, Vol. 23, No. 2, pp.145-158.

Davis, F. (1989) 'Perceived usefulness, perceived ease of use and user acceptance of information technology', MIS Quarterly, Vol. 13, No. 3, pp.319-339.

Ehrnberg, E. (1995) 'On the definition and measurement of technological discontinuities', Technovation, Vol. 15, No. 7, pp.437-452.

Ehrnberg, E. and Jacobsson, S. (1996) 'Managing technological discontinuities- a tentative framework', International Journal of Technological Management, Vol. 11, Nos. 3/4, pp.460-462.

Fishbein, M. and Ajzen, I. (1975) Belief, Attitude, Intention, and Behavior: An Introduction to Theory and Research, Addison-Wesley, Reading, MA.

Folkes, V. (1988) 'Recent attribution research in consumer behavior: a review and new directions', Journal of Consumer Research, Vol. 14, No. 3, pp.548-565.

Griffin, A. (1997) 'PDMA research on new product development practices: updating trends and benchmarking best practices', Journal of Product Innovation Management, Vol. 14, No. 6 , pp.429-458.

Guan, J.C., Mok, C.K., Yam, R.C.M., Chin, K.S. and Pun, K.F. (2006) 'Technology transfer and innovation performance: evidence from Chinese firms', Technological Forecasting and Social Change, Vol. 73, pp.666-678. 
Harris, P., Rettie, R. and Kwan, C.C. (2005) 'Adoption and usage of m-commerce: a cross-cultural comparison of Hong Kong and the United Kingdom', Journal of Electronic Commerce Research, Vol. 6, No. 3, pp.210-224.

Henry, J. and Stone, R. (1999) 'The impacts of end-user gender, education, performance, and system use on computer self-efficacy and outcome expectancy', Southern Business Review, Vol. 25, No. 1, pp.10-16.

Herr, P., Kardes, F. and Kim, J. (1991) 'Effects of word-of-mouth and product-attribute information on persuasion', Journal of Consumer Research, Vol. 17, No. 3, pp.458-462.

Holland, N. (2008) 'The state of mobile banking', Bank Systems and Technology, Vol. 45, No. 1, p.27.

Jeffres, L. and Atkin, D. (1996) 'Predicting use of technologies for consumer and communication needs', Journal of Broadcasting and Electronic Media, Vol. 40, No. 3, pp.318-330.

Kaufman, C. (1991) 'Coupon use in ethnic markets: Implications from a retail perspective', Journal of Consumer Marketing, Vol. 8, No. 1, pp.41-51.

Khan, J.H. and Ghani, J.A. (2004) 'Clusters and entrepreneurship: implications for innovation in a developing economy’, Journal of Developmental Entrepreneurship, Vol. 9, No. 3, pp.221- 238.

Kock, N. (2004) 'The psychobiological model: towards a new theory of computer-mediated communication based on Darwinian evolution', Organization Science, Vol. 15, No. 3, pp.327-348.

LaRose, R. and Eastin, M.S. (2004) 'A social cognitive theory of internet uses and gratifications: toward a new model of media attendance', Journal of Broadcasting and Electronic Media, Vol. 48, No. 3, pp.358-372.

Laukkanen, T. (2007) 'Customer preferred channel attributes in multi-channel electronic banking', International Journal of Retail and Distribution Management, Vol. 35, No. 5, pp.393-412.

Li, Y., Liu, Y. and Ren, F. (2007) 'Product innovation and process innovation in SOEs: evidence from the Chinese transition', Journal of Technology Transfer, Vol. 32, pp.63-85.

Lu, J., Yu, C., Liu, C. and Yao, J. (2003) 'Technology acceptance model for wireless internet, internet research', Electronic Networking Applications and Policy, Vol. 13, No. 3, pp.206-222.

Lundvall, B. and Borras, S. (1999) 'The globalising learning economy: implications for innovation policy', Office for Official Publications of the European Communities, Luxembourg.

Mathieson, K. (1991) 'Predicting user intentions: comparing the technology acceptance model with the theory of planned behavior', Information Systems Research, Vol. 2, No. 3, pp.173-191.

McCormick, M.J. and Martinko, M.J. (2004) 'Identifying leader social cognitions: integrating the causal reasoning perspective into social cognitive theory', Journal of Leadership and Organizational Studies, Vol. 10, No. 4, pp.2-11.

McCoy, S., Galletta, D.F. and King, W.R. (2007) 'Applying TAM across cultures: the need for caution', European Journal of Information Systems, Vol. 16, pp.81-90.

Mizerski, R. (1982) 'An attribution explanation of the disproportionate influence of unfavorable information', Journal of Consumer Research, Vol. 9, No. 12, pp.301-310.

Murmann, J.P. and Frenken, K. (2006) 'Toward a systematic framework for research on dominant designs, technological innovations, and industrial change', Research Policy, Vol. 35, pp.925-952.

O'Bannon, G. (2001) 'Managing our future: the generation X factor', Public Personnel Management, Vol. 30, No. 1, pp.95-109.

Pincus, J. (2004) 'The consequences of unmet needs: the evolving role of motivation in consumer research', Journal of Consumer Behavior, Vol. 3, No. 4, pp.375-387.

Ratten, V. (2008) 'Technological innovations in the m-commerce industry: a conceptual model of mobile banking intentions', Journal of High Technology Management Research, Vol. 18, No. 2, pp.111-117. 
Ratten, V. and Ratten, H. (2007) 'Social cognitive theory in technological innovation', European Journal of Innovation Management, Vol. 10, No. 1, pp.90-108.

Rice, B. and Bennet, R. (1998) 'The relationship between brand usage and advertising tracking measurements: international findings', Journal of Advertising Research, Vol. 38, No. 3, pp.58-66.

Riivari, J. (2005) 'Mobile banking: a powerful new marketing and CRM tool for financial services companies all over Europe', Journal of Financial Services Marketing, Vol. 10, No. 1, pp.11-20.

Roddick, H. (2003) 'True or false: faster innovation is better?', Working research, Lubin School of Business, Pace University, New York.

Rogers, E. (1995) Diffusion of Innovations, 4th ed., The Free Press of Glencoe, New York.

Rycroft, R.W. (2006) Time and Technological Innovation: Implications for Public Policy, Vol. 28, pp.281-301.

Salo, J. and Karjaluoto, H. (2007) 'Mobile games as an advertising medium: towards a new research agenda', Innovative Marketing, Vol. 3, No. 1, pp.71-82.

Schiffman, L. and Kanuk, L. (2000) Consumer Behavior, 7th ed., Prentice-Hall, New Jersey.

Scholnikoff, E.B. (2001) 'International governance in a technological age', in De la Mothe, J. (Ed.): Science, Technology and Governance, Continuum Press, New York.

Seitz, J. and Stickel, E. (1998) 'Internet banking-an overview', Journal of Internet Banking and Commerce, Vol. 3, No. 1, available at: http://www.arraydev.com/commerce/JIBC/9801-8.htm.

Sheth, J. Mittal, B. and Newman, B. (1999) Consumer Behavior: Consumer Behavior and Beyond, Dryden Press, Texas.

Snowden, S., Spafford, J., Michaelides, R. and Hopkins, J. (2006) 'Technology acceptance and $\mathrm{m}$-commerce in an operational environment', Journal of Enterprise Information Management, Vol. 19, No. 5, pp.525-539.

Stalk, J. and Hout, T.M. (1990) Competing Against Time: How Time-based Competition is Reshaping Global Markets, Free Press, New York.

Takac, P. (1997) 'The electronic bank-adding value without taking over', Australian Banker, Vol. 111, No. 4, pp.136-137.

Taylor, P. (2007) 'Money transfer by mobile phone plan', Financial Times, October 19, Vol. 8, London.

Taylor, S. and Todd, P. (1995) 'Understanding information technology usage: a test of competing models', Information Systems Research, Vol. 6, No. 2, pp.144-176.

The Economist (2007) 'Leaders: A bank in every pocket?', Mobile Banking, Vol. 385, No. 8555, November 17, p.16.

Venkatesh, V. and Davis, F.D. (1996) 'A model of the antecedents of perceived ease of use: development and test', Decision Sciences, Vol. 27, No. 3, pp.451-482.

Wexler, J. (2001) 'Why computer users accept new systems', MIT Sloan Management Review, Vol. 42, No. 3, p.17.

Wymbs, C. (2000) 'How e-commerce is transforming and internationalising service industries', Journal of Services Marketing, Vol. 14, No. 6, pp.463-478. 